\title{
MicroRNA-34a suppresses the invasion and migration of colorectal cancer cells by enhancing EGR1 and inhibiting vimentin
}

\author{
WEI ZHU $^{1 *}$, JIA-LI LONG ${ }^{1 *}$, YU-TING YIN ${ }^{1}$, HAI-NA GUO ${ }^{2}$, EN-PING JIANG ${ }^{1}$, \\ YU-LING $\mathrm{LI}^{3}$, QING-LIAN HE ${ }^{1}, \mathrm{CHAO} \mathrm{ZENG}^{1}$ and YAN-QIN SUN ${ }^{1}$ \\ ${ }^{1}$ Department of Pathology, Guangdong Medical University, Dongguan, Guangdong 523808; ${ }^{2}$ Department of Pathology, \\ Dongguan Maternal and Child Health Hospital, Dongguan, Guangdong 523002; ${ }^{3}$ Department of Pathology, \\ Dongguan Hospital of Southern Medical University, Dongguan, Guangdong 523059, P.R. China
}

Received October 11, 2018; Accepted June 6, 2019

DOI: $10.3892 / \mathrm{etm} .2019 .7826$

\begin{abstract}
MicroRNAs (miRNAs/miRs) are small non-coding RNAs that serve a post-transcriptional regulatory role in eukaryotes. Previous studies have demonstrated that the expression of miR-34a in colorectal cancer (CRC) tissues is decreased compared with that in normal colorectal tissues. However, the role of miR-34a in the invasion and metastasis of CRC remains unclear. In the present study, the levels of miR-34a expression were measured in various CRC cell lines. The cells were transfected with miR-34a mimics or inhibitors in order to assess the proliferation rate, and the colony forming, invasive and migratory abilities. Furthermore, the protein expression levels of vimentin and early growth response protein 1 (EGR1) were examined by western blot analysis. The results revealed that the expression of miR-34a was low in SW620, RKO, LoVo and Caco-2 cell lines and high in the SW480 and SW1116 cell lines. The migration, invasion and proliferation levels of SW480 cells were facilitated by decreasing the expression of miR-34a. Transient transfection with miR-34a mimics in SW620 cells caused a notable decrease in cell migration, invasion and proliferation levels compared with the control group, and a downregulation of vimentin and upregulation of EGR1 protein expression. The present study demonstrated that miR-34a was deregulated in a highly invasive CRC cell lines, and that it may attenuate the migratory, invasive and proliferative capabilities of CRC cells by enhancing the expression of EGR1 and inhibiting that of vimentin. The results of the present study represent important
\end{abstract}

Correspondence to: Dr Yan-Qin Sun or Dr Chao Zeng, Department of Pathology, Guangdong Medical University, 1 Xincheng Road, Dongguan, Guangdong 523808, P.R. China

E-mail: sunyanqin1688@126.com

E-mail: zengchaosysu@126.com

${ }^{*}$ Contributed equally

Key words: microRNA-34a, early growth response protein 1, metastasis, invasion, colorectal cancer progress towards understanding the mechanisms of CRC recurrence and metastasis.

\section{Introduction}

Colorectal cancer (CRC) is the third most common cancer worldwide, accounting for $\sim 1.4$ million incident cases and 600,000 mortalities every year (1). The low early diagnosis rate, high recurrence and metastasis rates, and lack of effective treatment are responsible for the CRC-associated mortality statistics (2). Therefore, the identification of the molecular mechanisms involved in the progression of CRC would be useful in providing targets for cancer detection, prevention and therapy, and ultimately improving patient prognosis.

MicroRNAs (miRNAs/miRs) are a small non-coding RNA molecules present in plants, animals and certain viruses, and they serve a role in RNA silencing and post-transcriptional regulation of gene expression $(3,4)$. In animal cells, the miRNA gene first transcribes a longer primary miRNA in the nucleus, where it is processed by the Drosha enzyme to form a 60-70 nucleotide hairpin precursor miRNA. This is transported to the cytoplasm with the help of the nuclear exportin-5 complex, and cleaved by the Dicer protein to generate a mature miRNA of 18-25 nucleotides. Mature miRNAs and a number of proteins form RNA silencing complexes, which inhibit transcription or translation of the target gene through the activity of sequences complementary to the 3'untranslated region of the target gene mRNA that are contained within the complex $(5,6)$. It has been established that miRNAs are important regulators of apoptosis, cell proliferation and tumorigenesis (7-10).

miR-34a is considered to be a potential tumor suppressor miRNA based on its frequent dysregulation in cancer tissues (11) and its ability to regulate the expression of numerous genes, including NOTCH1, apoptosis regulator BCL2, MYC protooncogene, MET proto-oncogene, cyclin-dependent kinases 4/6 and CD44 antigen (12-14). miR-34a is frequently downregulated in multiple types of cancer and is an independent prognostic indicator in various types of cancer, including colon, breast, lung and gastric cancer (15-18). In addition, it is significantly downregulated in the serum and tumor tissue in CRC $(19,20)$. However, the exact molecular mechanism of miR-34a in the development of $\mathrm{CRC}$ has not been fully elucidated. In the present study, miR-34a 
was inhibited or overexpressed in CRC cells, revealing that it inhibited cell migration, invasion and proliferation by regulating vimentin and early growth response protein 1 (EGR1).

\section{Materials and methods}

Cell lines and culture. Human CRC cell lines SW480, SW620, RKO, LoVo and SW1116 were provided by Sun Yat-sen University (Guangzhou, China) and grown in RPMI-1640 medium (Gibco; Thermo Fisher Scientific, Inc.) supplemented with 10\% FBS (Sera Gold), $100 \mathrm{U} / \mathrm{ml}$ penicillin $\mathrm{G}$ and $100 \mathrm{mg} / \mathrm{ml}$ streptomycin (Gibco; Thermo Fisher Scientific, Inc.). The human CRC Caco-2 cell line and the human colonic epithelial NCM460 cell line were provided by Sun Yat-sen University and grown in Dulbecco's modified Eagle's medium (Gibco, Thermo Fisher Scientific, Inc.) with 10\% FBS. The cells were cultured at $37^{\circ} \mathrm{C}$ in a $5 \% \mathrm{CO}_{2}$ incubator. Detailed information on cell lines is summarized in Table SI.

Reverse transcription quantitative polymerase chain reaction $(R T-q P C R)$. Total RNA from the cultured cancer cells was extracted using TRIzol ${ }^{\circledR}$ reagent (Invitrogen, Thermo Fisher Scientific, Inc.). cDNA was then synthesized from total RNA or small RNA using the Prime-Script RT reagent kit (Takara Bio, Inc.) or via the stem-loop method using the miRNA First Strand cDNA Synthesis kit (Sangon Biotech Co., Ltd., Shanghai, China). The qPCR was performed using $2 X$ SG Fast qPCR Master Mix (Sangon Biotech Co., Ltd.) according to the manufacturer's protocol. The following thermocycling conditions were used for qPCR: Initial denaturation at $95^{\circ} \mathrm{C}$ for $3 \mathrm{~min}$, followed by 40 cycles at $95^{\circ} \mathrm{C}$ for $5 \mathrm{sec}$ and at $60^{\circ} \mathrm{C}$ for $30 \mathrm{sec}$. The following primers were utilized for qPCR: miR-34a forward, 5'-CCGCGTGGCAGTGTCTTAGCT-3' and reverse, 5'-ATCCAGTGCAGGGTCCGAGG-3'; U6 forward, 5'-CTCGCTTCGGCAGCACA-3' and reverse, 5'-AACGCT TCACGAATTTGCGT-3' (each, Sangon Biotech Co., Ltd.). For each case, $\geq 3$ biological replicates were performed. The qPCR analysis was performed on a PikoReal ${ }^{\mathrm{TM}}$ (Thermo Fisher Scientific, Inc.). The miRNA was quantified with the $2^{-\Delta \Delta \mathrm{Cq}}$ method and normalized against U6 (21).

Oligonucleotide transient transfection. SW480 and SW620 cells were seeded into 6-well plates at a density of $3 \times 10^{5}$ cell per well. Prior to transfection, cells were plated at $70-80 \%$ confluence. miR-34a mimic, inhibitor and corresponding negative control were chemically synthesized by Guangzhou RiboBio (Guangzhou RiboBio Co., Ltd.). The mimic and inhibitor sequences were as follows: miR-34a mimic, 5'-UGG CAGUGUCUUAGCUGGUUGU-3'; control miR-34a mimic, 5'-UUUGUACUACACAAAAGUACUG-3'; miR-34a inhibitor, 5'-ACAACCAGCUAAGACACUGCCA-3' and control miR-34a inhibitor, 5'-UCACAACCUCCUAGAAAG AGUAGA-3'. The SW620 cells were transfected with $50 \mathrm{nM}$ miR-34a mimic (named miR-34a) or mimic negative control (NC) (Guangzhou RiboBio Co., Ltd.) by nucleofection using Lipofectamine ${ }^{\circledR} 3000$ (Invitrogen, Thermo Fisher Scientific, Inc.), and the SW480 cells were transfected with $100 \mathrm{nM}$ miR-34a inhibitor (inmiR-34a) or inhibitor NC, according to the manufacturer's protocol. At $24 \mathrm{~h}$ post-transfection, RT-qPCR was performed to verify the transfection efficiency.
Western blot analysis. SW480 and SW620 cells were collected $48 \mathrm{~h}$ after the aforementioned transfections. Protein was extracted from cells using a mixture of RIPA lysate (Beyotime Institute of Technology), PMSF (Beyotime Institute of Technology) and 50x phosphatase inhibitor (Applygen Technologies, Inc.) at a ratio of 100:1:2. Protein concentrations were then quantified using a BCA Protein Assay kit (Thermo Fisher Scientific, Inc.). A total of $40 \mu \mathrm{g}$ protein was separated by $10 \%$ SDS-PAGE (Beyotime Institute of Technology) and subsequently transferred to polyvinylidene difluoride membranes (Merck KGaA). The membranes were blocked with low-fat milk (5\%) at room temperature for $1 \mathrm{~h}$, and then incubated at $4^{\circ} \mathrm{C}$ overnight with primary antibodies against EGR1 (cat. no. 4153; 1:1,000; Cell Signaling Technology, Inc.), vimentin (cat. no. 5741; 1:1,000; Cell Signaling Technology,Inc.) and GAPDH (cat. no. 5174; 1:1,000; Cell Signaling Technology, Inc.). Subsequently, the membranes were washed with TBST 3 times and incubated with a horseradish peroxidase-conjugated goat anti-rabbit secondary antibody (cat. no. A0208; 1:1,000; Beyotime Institute of Biotechnology) for $1 \mathrm{~h}$ at room temperature. Following 3 washes with TBST, the results were detected using an enhanced chemiluminescence system on a FluorChem R (ProteinSimple). Protein expression was quantified using ImageJ software (version 1.47; National Institutes of Health).

Wound healing assay. SW480 and SW620 cells were cultured in 6-well plate following transfection until the confluence reached $90 \%$. The cell monolayers were scratched with micropipette tips to form a gap. The cell culture surface was washed 3 times with PBS to remove cellular debris and incubated in RPMI-1640 medium with 2\% FBS for $48 \mathrm{~h}$. The wound closures were compared at 0 and $48 \mathrm{~h}$. Images were captured using an optical microscope (magnification, x100; Nikon Corporation) and analyzed with ImageJ software (version 1.47; National Institutes of Health).

Transwell cell migration assay. Following $12 \mathrm{~h}$ of transfection, SW480 and SW620 cells were treated with $0.25 \%$ trypsin (Beijing Solarbio Science \& Technology Co., Ltd.) and suspended in serum-free RPMI-1640 medium at a density of $3 \times 10^{5} \mathrm{cells} / \mathrm{ml}$. A total of $200 \mu \mathrm{l}$ cell suspension was placed in the top chamber of a 2-chamber Costar Transwell 24-well plates (8- $\mu \mathrm{m}$ pores; Corning Inc.) and $600 \mu \mathrm{l}$ RPMI-1640 medium containing $15 \%$ FBS was added in the lower chamber. The cells were cultured at $37^{\circ} \mathrm{C}$ for $48 \mathrm{~h}$. The cells on the surface of the upper chamber were swabbed and those under the surface of the lower chamber were stained with crystal violet $(0.1 \%)$ at room temperature for $20 \mathrm{~min}$. Cell migration was evaluated by counting the cells that had migrated into the filters using an optical microscope (magnification, x100; Nikon Corporation).

Transwell cell invasion assay. The invasion assay was performed using the aforementioned migration assay protocol, but following the addition of $50 \mu \mathrm{l} \mathrm{BD}$ Matrigel ${ }^{\mathrm{TM}}$ (BD Biosciences) into each Transwell upper chamber, which was then placed in a $37^{\circ} \mathrm{C}$ incubator for $2 \mathrm{~h}$ to solidify. The tumor cell invasive capacity was then assessed as aforementioned.

Colony formation assay. Following transfection for $12 \mathrm{~h}$, the SW480 and SW620 cells were transferred to 6-well plates with 

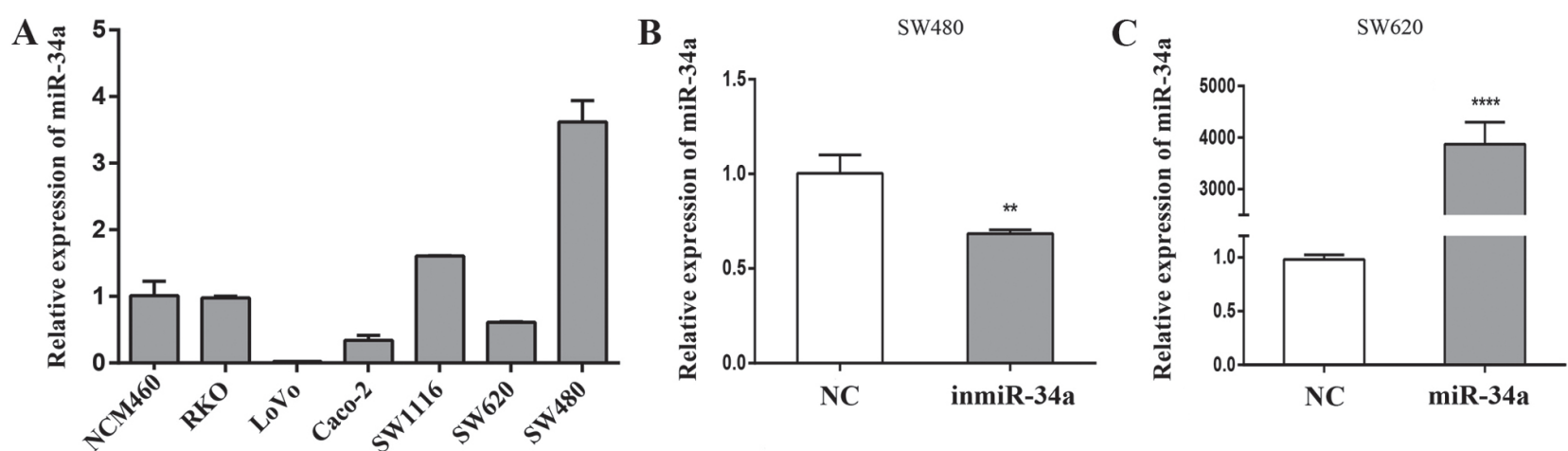

Figure 1. Expression of miR-34a in CRC cell lines and evaluation of miR-34a mimic and inhibitor transfection efficiency. (A) The expression of miR-34a in 7 cell lines was assessed by RT-qPCR (6 CRC cell lines and NCM460 as the normal control). (B and C) At 24 h post-transfection, RT-qPCR was performed to verify the transfection efficiency. Compared with the equivalent NC group, the expression of miR-34a was (B) significantly decreased in SW480 cells with inmiR-34a and (C) significantly increased in SW620 cells with miR-34a mimic. ${ }^{* *} \mathrm{P}<0.01$ and ${ }^{* * * * *} \mathrm{P}<0.0001$ vs. the equivalent NC groups. miR, microRNA; CRC, colorectal cancer; RT-qPCR, reverse transcription-quantitative polymerase chain reaction; NC, negative control; inmiR-34a, miR-34a inhibitor group.

RPMI-1640 medium with $10 \%$ FBS (300 cells per well). The cells were cultured at $37^{\circ} \mathrm{C}$ and $5 \% \mathrm{CO}_{2}$ for 2 weeks. Subsequently, the cell colonies were fixed with pure methanol for $15 \mathrm{~min}$ at room temperature and stained with $0.1 \%$ crystal violet for $20 \mathrm{~min}$ at room temperature, and the colonies were counted.

MTT assay. Following transfection for $12 \mathrm{~h}, \mathrm{SW} 480$ and SW620 cells in each group were transferred to a 96-well plate and cultured at $37^{\circ} \mathrm{C}$, and $5 \% \mathrm{CO}_{2}$ for $72 \mathrm{~h}$. The MTT assay was performed at $0,24,48$ and $72 \mathrm{~h}$. At each time point, the medium was replaced and $20 \mu \mathrm{l}$ MTT $(5 \mathrm{mg} / \mathrm{ml})$ was added to each well. Following incubation at $37^{\circ} \mathrm{C}$ for $4 \mathrm{~h}$, the medium was discarded and $150 \mu 1$ dimethyl sulfoxide (Beijing Solarbio Science \& Technology Co., Ltd.) was added to each well. The optical density was measured at $490 \mathrm{~nm}$.

Statistical analysis. Statistical analysis was performed using SPSS version 17.0 (SPSS Inc.) and GraphPad Prism version 6.0 (GraphPad Software, Inc.). The data are presented as mean \pm standard deviation. A Student's t-test was used for comparison between two groups. $\mathrm{P}<0.05$ was considered to indicate a statistically significant difference.

\section{Results}

miR-34a is deregulated in highly invasive cells, and may be successfully transfected into SW620 and SW480 cells. RT-qPCR was used to detect the levels of miR-34a in CRC and normal colonic epithelial cells. The expression of miR-34a in highly invasive CRC SW620, RKO and LoVo cell lines is presented in Fig. 1A. The SW620 cell line was derived from a lymph node metastasis of a primary colon tumor, whereas cells from the primary colon tumor in the same patient were used to establish the SW480 cell line. These 2 cell lines were selected for subsequent experiments to observe any notable contrasts. At $24 \mathrm{~h}$ post-transfection, RT-qPCR was performed to verify the transfection efficiency. Compared with the equivalent NC group, differences were observed in the levels of relative miR-34a expression following transfection of the inmiR-34a in the SW480 cells $(\mathrm{P}<0.01$; Fig. $1 \mathrm{~B})$, and miR-34a mimic into the SW620 cells $(\mathrm{P}<0.001$; Fig. 1C).
miR-34a suppresses the migration and invasion of CRC cells. The effect of miR-34a on the migratory and invasive abilities of SW480 and SW620 cell was assessed. The migratory ability of the inmiR-34a group was significantly more marked compared with that of the NC group $(\mathrm{P}<0.001$; Fig. 2A). Furthermore, the overexpression of miR-34a in SW620 cells attenuated cell migration $(\mathrm{P}<0.05$; Fig. $2 \mathrm{~B})$. The inmiR-34a group of the SW480 cells exhibited a significant increase in cell invasion ( $\mathrm{P}<0.001$; Fig. 2C), whereas the increased levels of miR-34a in SW620 cells led to a decrease $(\mathrm{P}<0.05$; Fig. 2D). In addition, the wound healing assay was performed to evaluate the migration of SW480 cells and SW620 cells. Compared with the equivalent control groups, the degree of wound closure was increased in inmiR-34a group (Fig. 3A), and decreased in the SW620 mimic group (Fig. 3B).

miR-34a inhibits the proliferation of CRC cells. The proliferation of SW480 and SW620 cells following transfection of miR-34a was examined. The results from the MTT assay revealed an increased proliferative ability in the SW480 inmiR-34a group compared with the NC group, whereas a decrease in the proliferation rate was observed in the SW620 cells with miR-34a overexpression (Fig. 4). The colony-formation rate for the SW480 inmiR-34a group was $47.11 \pm 2.75 \%$, compared with $27.78 \pm 4.41 \%$ for the NC group $(\mathrm{P}<0.05$; Fig. $5 \mathrm{~A})$. In the SW620 cells, the colony formation rate of miR-34a mimic group was $29.44 \pm 4.68 \%$, compared with $45.56 \pm 1.98 \%$ in the NC group $(\mathrm{P}<0.05$; Fig. 5B). The colony formation ability of the SW480 inmiR-34a and the SW620 NC groups was improved compared with that of the groups to which they were compared, and their colony sizes were larger.

miR-34a suppresses the expression of vimentin and increases the expression of EGR1. The results of the western blot analysis revealed that the expression of EGR1 protein was increased in the miR-34a group of SW620 cells compared with the NC group $(\mathrm{P}<0.05)$, whereas the expression of vimentin was decreased $(\mathrm{P}<0.01$; Fig. $6 \mathrm{~A})$. By contrast, compared with the NC group, the EGR1 level was decreased in the inmiR-34a group of the SW480 cells $(\mathrm{P}<0.05)$, and the level of vimentin was increased $(\mathrm{P}<0.001$; Fig. $6 \mathrm{~B})$. 

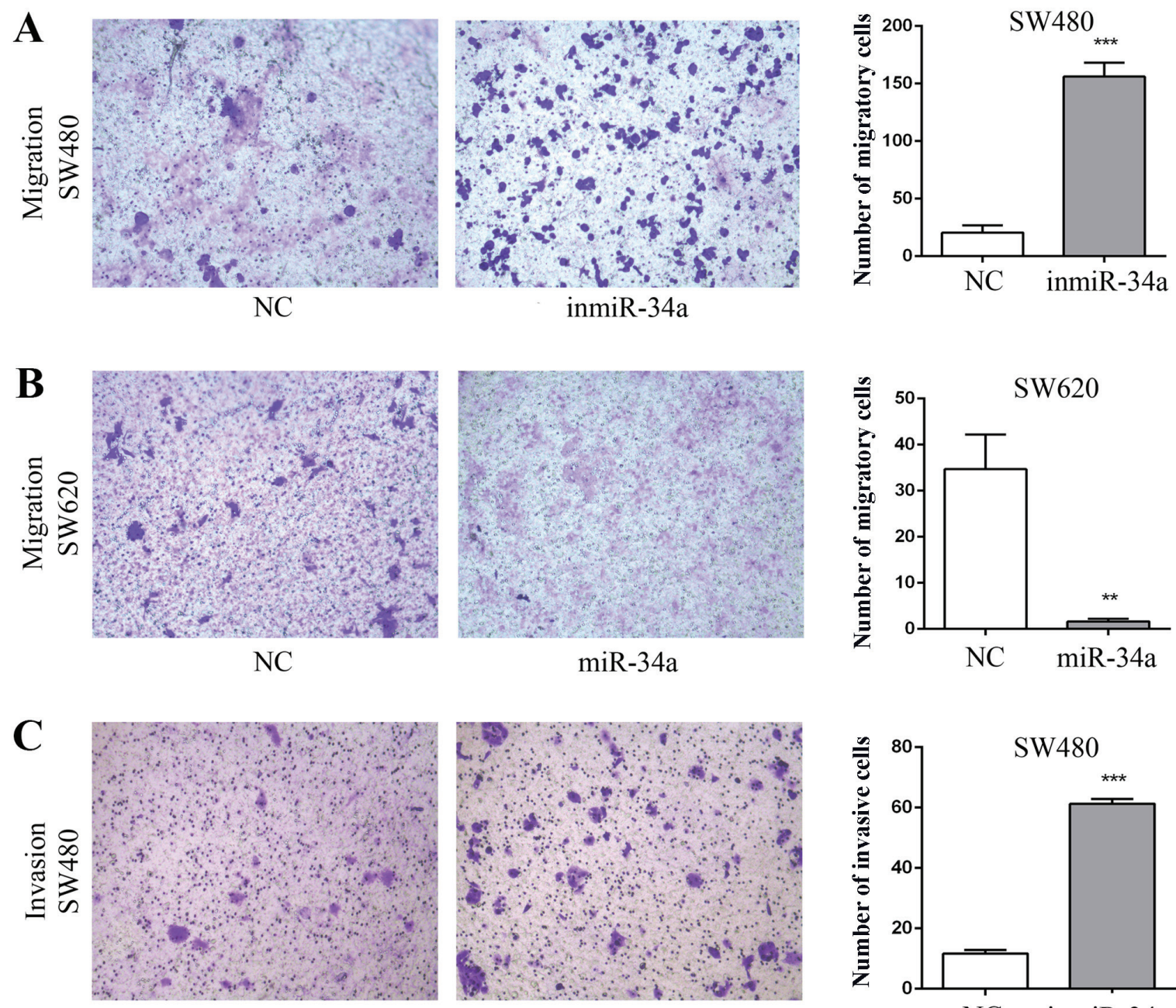

$\mathrm{NC}$
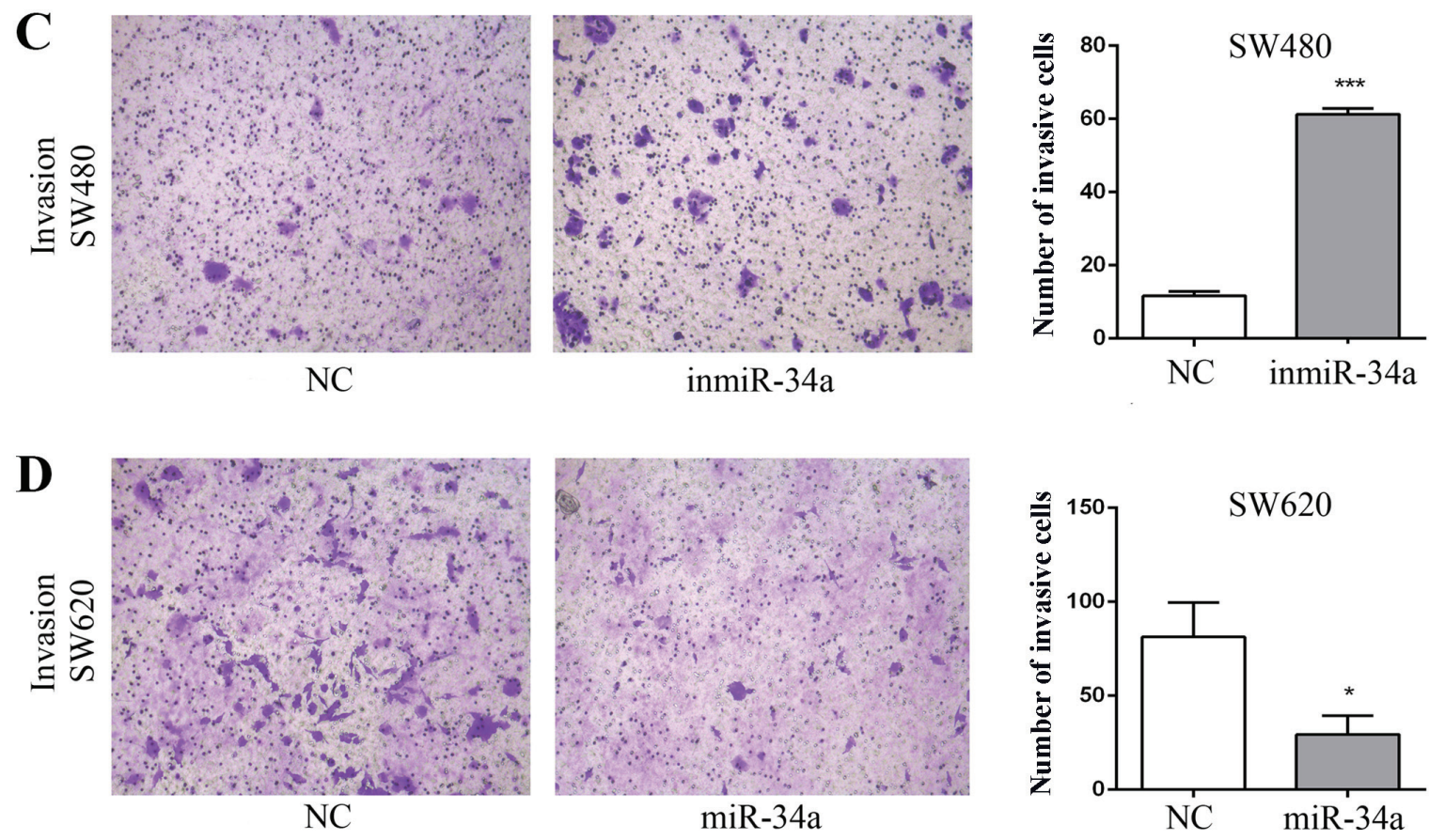

Figure 2. miR-34a suppresses the migration and invasion of colorectal cancer cells. The migration and invasion of SW480 and SW620 cells with and without inmiR-34a or miR-34a mimic transfection was examined using Transwell assays. The left panel is comprised of representative cell images at magnification, x100. The SW480 cells and SW620 cells in 5 randomly selected areas were counted and statistical analyses were performed (right panel). The data are expressed as the mean \pm standard deviation. (A) The migration of SW480 cells transfected with inmiR-34a and NC. (B) The migration of SW620 cells transfected with miR-34a mimic and NC. (C) The invasion of SW480 cells transfected with inmiR-34a and NC. (D) The invasion of SW620 cells transfected with miR-34a mimic and NC. The cell migratory and invasive abilities of the SW480 inmiR-34a group were significantly increased compared with that of the NC group, and the cell migratory and invasive abilities of the SW620 miR-34a group were significantly decreased compared with that NC group of cells. "P<0.05, ${ }^{* *} \mathrm{P}<0.01$ and ${ }^{* * *} \mathrm{P}<0.001$ vs. the equivalent $\mathrm{NC}$ groups. miR, microRNA; NC, negative control; inmiR-34a, miR-34a inhibitor group.

\section{Discussion}

CRC is the third most common cancer worldwide, and its incidence and mortality are increasing globally (2). CRC is a heterogeneous disease; its progression is caused by special genetic alterations. The identification of the molecular mechanisms involved in the progression of CRC would assist in providing targets for cancer prevention and therapy, and improving patient prognosis. The potential tumor suppressor miRNA miR-34a is frequently downregulated in a number of types of cancer (12-14). The results of the present study demonstrated that miR-34a is deregulated in highly invasive CRC cell lines. Increasing the expression of miR-34a in SW620 cells inhibited the cell proliferative, migratory and 
A

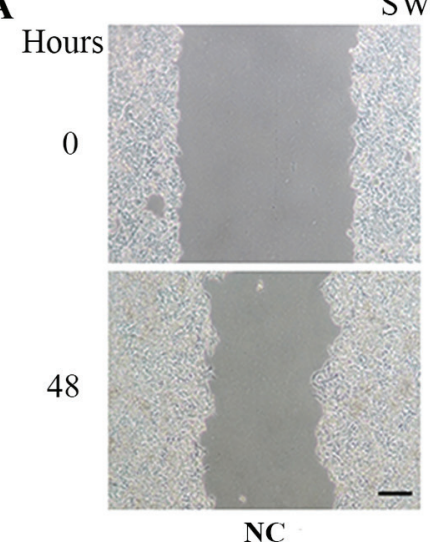

SW480

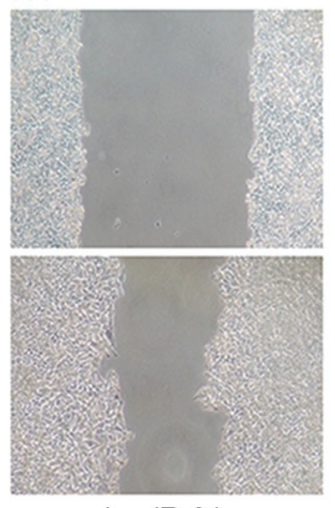

inmiR-34a
B

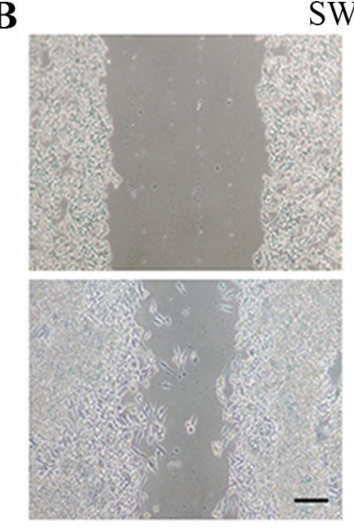

$\mathrm{NC}$
SW620

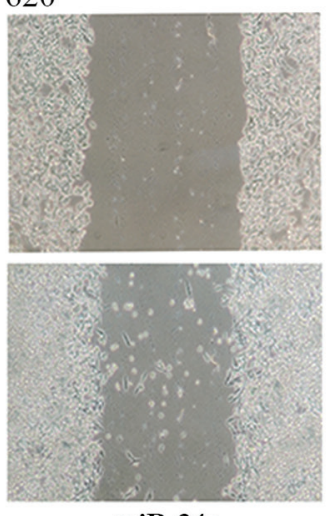

Figure 3. miR-34a suppresses the migration of colorectal cancer cells in a wound healing assay. (A) Representative images of the scratch test in SW480 cells transfected with inmiR-34a inhibitor or inhibitor NC at 0 and $48 \mathrm{~h}$. (B) Representative images of the scratch test in SW620 cells transfected with a miR-34a mimic or mimic NC at 0 and $48 \mathrm{~h}$. Scale bar=100 $\mu \mathrm{m}$. miR, microRNA; NC, negative control; inmiR-34a, miR-34a inhibitor group.
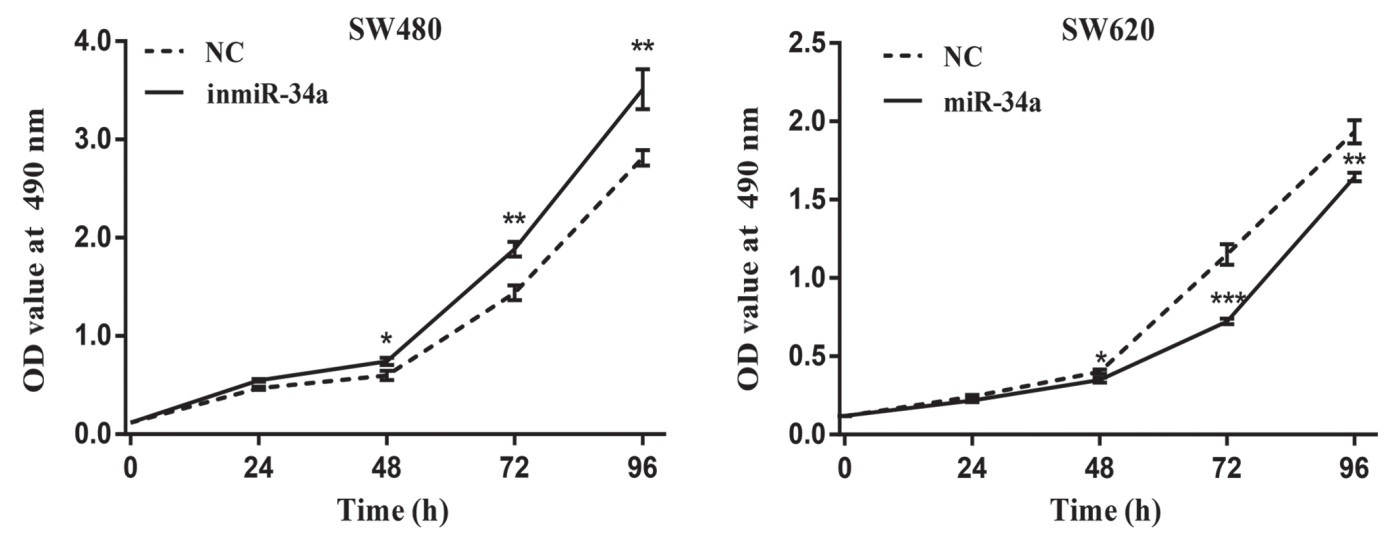

Figure 4. miR-34a inhibits the proliferation of colorectal cancer cells. Cell proliferation was assessed by an MTT assay following the downregulation of miR-34a in SW480 cells and the overexpression in SW620 cells. The data indicates that miR-34a downregulation increased the cell proliferation rate, whereas miR-34a overexpression led to a decrease in proliferation rate. ${ }^{*} \mathrm{P}<0.05,{ }^{* * *} \mathrm{P}<0.01$ and ${ }^{* * * *} \mathrm{P}<0.001$ vs. NC at each time point. miR, microRNA; NC, negative control; inmiR-34a, miR-34a inhibitor group; OD, optical density.

invasive capabilities of these cells. Furthermore, it suppressed the expression of vimentin and increased the expression of EGR1. The opposite effects were observed when miR-34a was inhibited in SW480 cells.

EGR1 is a 59-kDa zinc finger transcription factor that appears to activate transcription by binding to DNA as a monomer (22). EGR1 is also known to exhibit a tumor suppressor function in a variety of human tumors, including lung and breast cancer, glioblastoma and ovarian cancer (23-25). Furthermore, previous studies have indicated that EGR1 is a direct regulator of at least 4 major suppressors: Transforming growth factor $\beta-1$ protein, PTEN, cellular tumor antigen p53 family members and fibronectin, being involved in the regulation of the invasive behavior of cancer cells (26-28). It was also demonstrated that sustained EGR1 expression may lead to preferential inhibition of tumor cell invasion and tumor growth (29). However, few studies have focused on EGR1 in CRC. In the present study, the addition of a miR-34a mimic caused the expression of EGR1 to increase in CRC cell lines. Therefore, EGR1 is considered to be involved in the mechanism of miR-34a in suppressing tumorigenesis and development of CRC. The results from the present study revealed that miR-34a overexpression enhanced EGR1 levels in SW620 cells, whereas inhibition of miR-34a in SW480 cells elicited the opposite effect. However, the mechanism of how EGR1 participates in regulation of the invasion and metastasis of CRC by miR-34a requires additional investigation.

Vimentin, an intermediate silk protein, is involved in cell structure and integrity (30). Previous studies have revealed that it is abnormally expressed in numerous cancer types and that it affects the shape and movement of cancer cells during the epithelial-mesenchymal transition (EMT) process. Therefore, it is considered to be a potential cancer therapeutic target (31-33). The EMT is a biological phenomenon in which epithelial cells lose their epithelial properties and acquire interstitial cell characteristics under certain circumstances (34), and it has been revealed that it is one of the mechanisms of tumor cell invasion and metastasis (35). Notably, vimentin is involved in the EMT (36). A previous study demonstrated that the expression levels of vimentin in paraffin-embedded CRC specimens were significantly increased compared with those in non-tumor adjacent tissues, and that the high vimentin expression is associated with various adverse clinicopathological factors (37). 

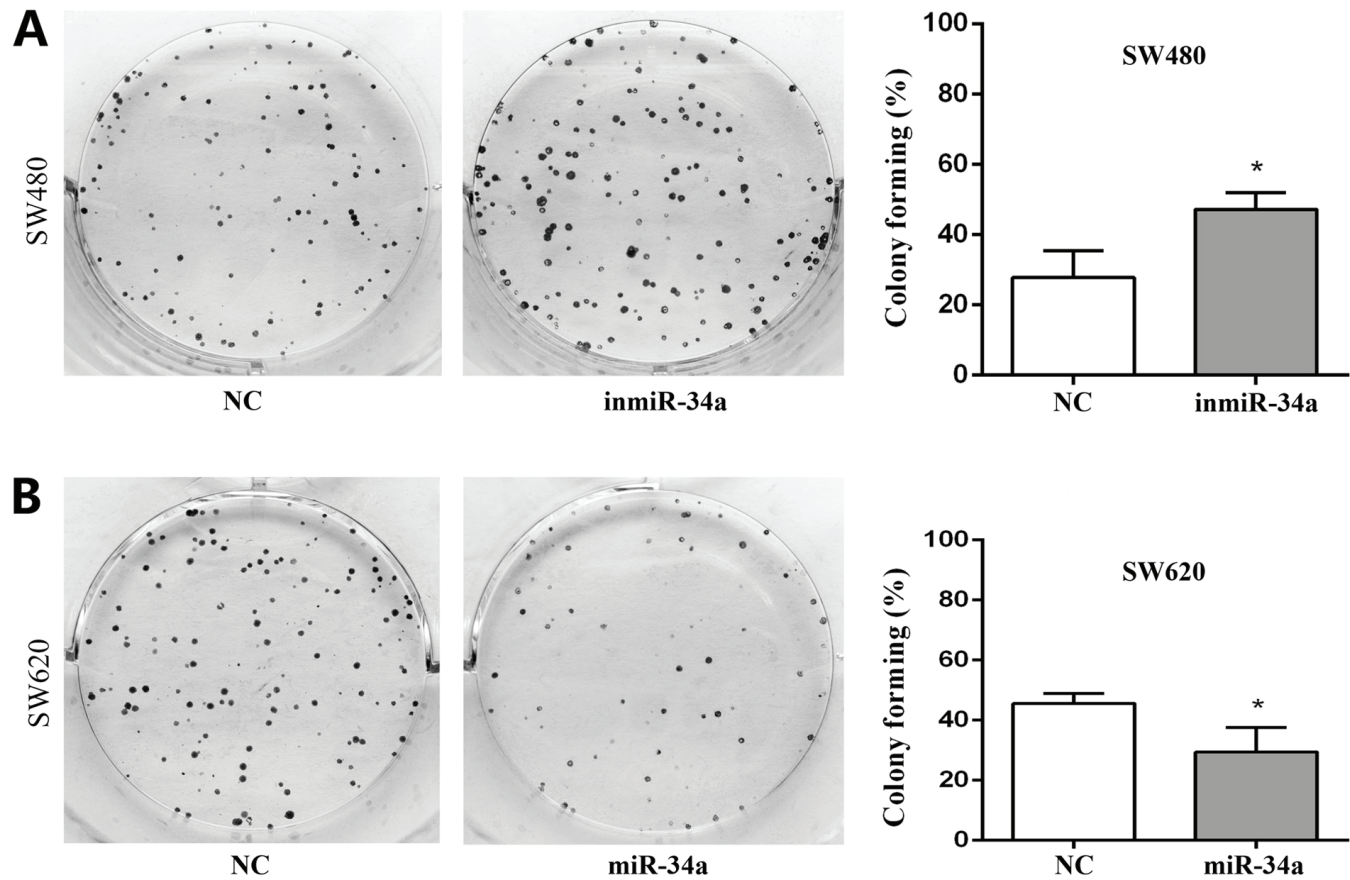

Figure 5. miR-34a inhibits the proliferation of colorectal cancer cells in a colony formation assay. Compared with the equivalent $\mathrm{NC}$ groups, the ability of colony formation was (A) increased in the inmiR-34a cells and (B) decreased in the cells with miR-34a overexpression. ${ }^{*} \mathrm{P}<0.05 \mathrm{vs}$. NC. miR, microRNA; $\mathrm{NC}$, negative control; inmiR-34a, miR-34a inhibitor group.

A

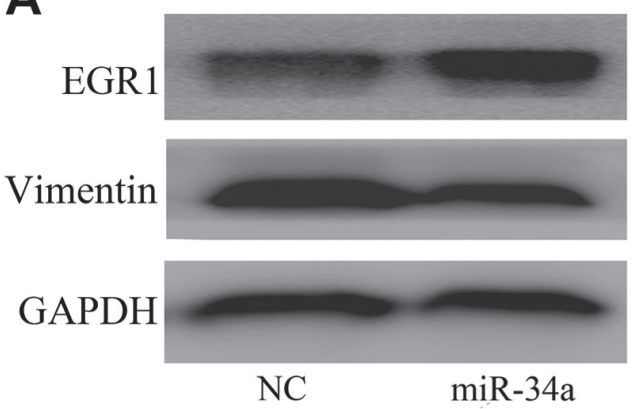

B

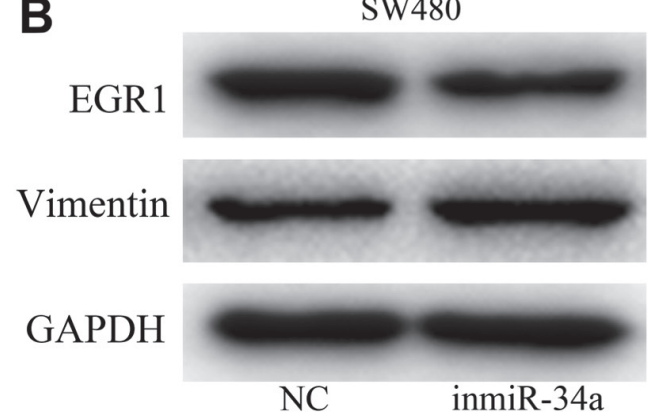

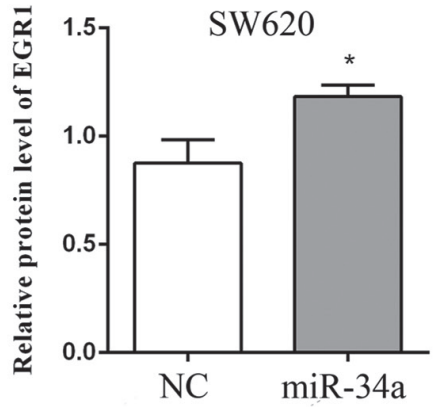
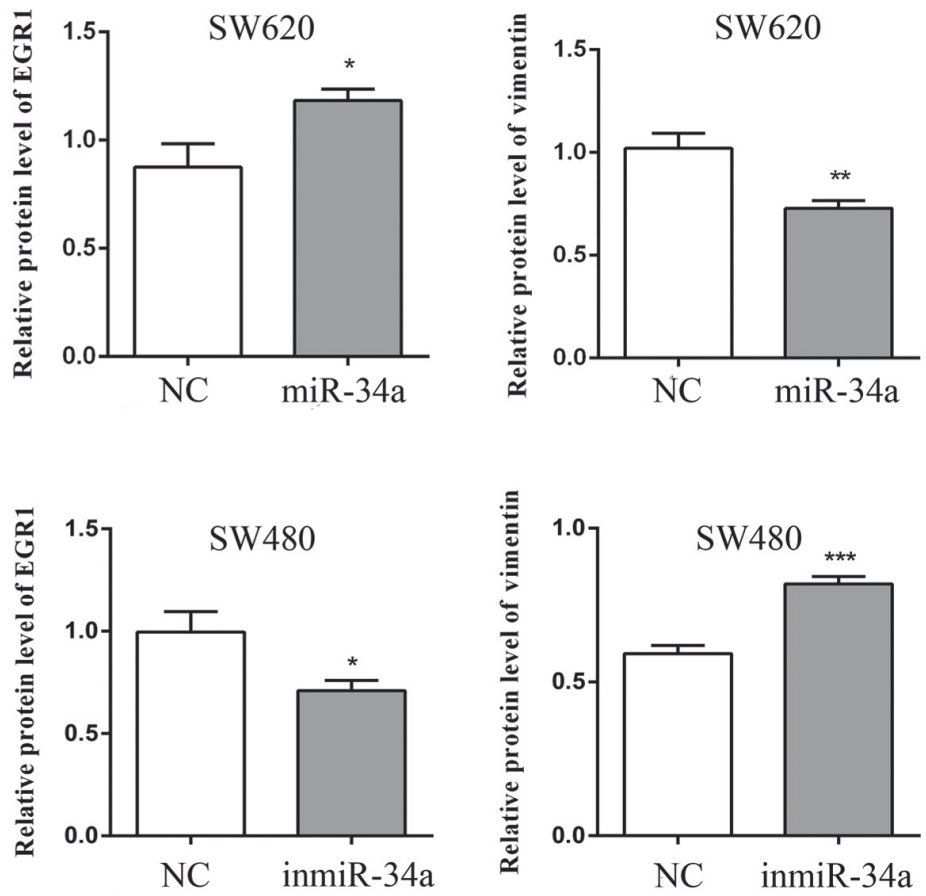

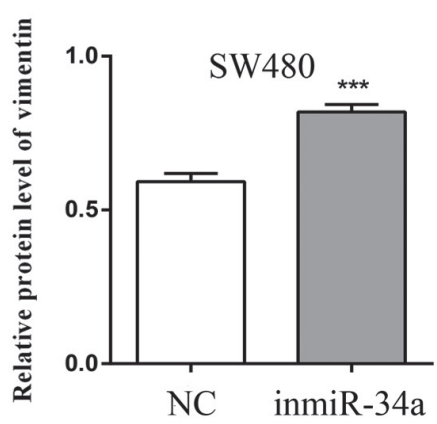

Figure 6. Western blot analysis of the protein expression of EGR1 and vimentin in SW620 and SW480 cells. (A) The expression of EGR1 was increased in the miR-34a overexpression group, whereas the expression of vimentin was decreased. (B) The expression of EGR1 was decreased in the inmiR-34a group, whereas the expression of vimentin was increased. ${ }^{*} \mathrm{P}<0.05,{ }^{* *} \mathrm{P}<0.01$ and ${ }^{* * * *} \mathrm{P}<0.001$ vs. the equivalent NC. EGR1, early growth response protein 1 ; miR, microRNA; NC, negative control; inmiR-34a, miR-34a inhibitor group.

Furthermore, the expression of vimentin in CRC tissues is significantly increased in patients with higher tumor stage, lymph node involvement, liver metastasis and advanced tumor-node-metastasis stages (38). During the previous few years, miR-34a has been revealed to be involved in the EMT regulation and, therefore, to affect the invasion and metastasis of tumors (39). The results of the present study indicate that miR-34a overexpression inhibits the expression of vimentin in SW620 cells, and miR-34a inhibition leads to an increase in vimentin in SW480 cells. 
In conclusion, the results of present study support the hypothesis that miR-34a suppresses the cell migration, invasion and proliferation of CRC cells by regulating vimentin and EGR1. This suggests that miR-34a may prove to be a novel molecular target for the treatment of CRC.

\section{Acknowledgements}

Not applicable.

\section{Funding}

The present study was supported by the National Natural Science Foundation of China (grant nos. 81472275, 81702285 and 81702399) and the Natural Science Foundation of Guangdong Province (grant nos. 2014A030313542 and 2017A030313644).

\section{Availability of data and materials}

The datasets used and/or analyzed during the present study are available from the corresponding author on reasonable request.

\section{Authors' contributions}

JL, YY and QH performed the experiments. WZ, CZ and YS designed the current study. JL, YS and EJ analyzed the data. JL and WZ wrote the manuscript. HG and YL provided technical assistance and participated in critical revisions of important intellectual content in the manuscript. WZ, JL, EJ and YS revised the manuscript. All authors have read and approved the final version of this manuscript.

\section{Ethics approval and consent to participate}

Not applicable.

\section{Patient consent for publication}

Not applicable.

\section{Competing interests}

The authors declare that they have no competing interests.

\section{References}

1. Jemal A, Bray F, Center MM, Ferlay J, Ward E and Forman D: Global cancer statistics. CA Cancer J Clin 61: 69-90, 2011.

2. Ung L, Lam AK, Morris DL and Chua TC: Tissue-based biomarkers predicting outcomes in metastatic colorectal cancer: A review. Clin Transl Oncol 16: 425-435, 2014.

3. Ambros V: The functions of animal microRNAs. Nature 431: 350-355, 2004

4. Bartel DP: MicroRNAs: Genomics, biogenesis, mechanism, and function. Cell 116: 281-297, 2004.

5. Bartel DP: MicroRNAs: Target recognition and regulatory functions. Cell 136: 215-233, 2009.

6. Meijer HA, Kong YW, Lu WT, Wilczynska A, Spriggs RV, Robinson SW, Godfrey JD, Willis AE and Bushell M Translational repression and eIF4A2 activity are critical for microRNA-mediated gene regulation. Science 340: 82-85, 2013.

7. Esquela-Kerscher A and Slack FJ: Oncomirs-microRNAs with a role in cancer. Nat Rev Cancer 6: 259-269, 2006.
8. Lin S and Gregory RI: MicroRNA biogenesis pathways in cancer. Nat Rev Cancer 15: 321-333, 2015.

9. Zhu J, Zou Z, Nie P, Kou X, Wu B, Wang S, Song Z and He J: Downregulation of microRNA-27b-3p enhances tamoxifen resistance in breast cancer by increasing NR5A2 and CREB1 expression. Cell Death Dis 7: e2454, 2016.

10. Ao X, Nie P, Wu B, Xu W, Zhang T, Wang S, Chang H and Zou Z: Decreased expression of microRNA-17 and microRNA-20b promotes breast cancer resistance to taxol therapy by upregulation of NCOA3. Cell Death Dis 7: e2463, 2016.

11. Tazawa $H$, Tsuchiya $N$, Izumiya $M$ and Nakagama $H$ : Tumor-suppressive miR-34a induces senescence-like growth arrest through modulation of the E2F pathway in human colon cancer cells. Proc Natl Acad Sci USA 104: 15472-15477, 2007.

12. Rokavec M, Li H, Jiang L and Hermeking H: The p53/miR-34 axis in development and disease. J Mol Cell Biol 6: 214-230, 2014.

13. Slabáková E, Culig Z, Remšík J and Souček K: Alternative mechanisms of miR-34a regulation in cancer. Cell Death Dis 8: e3100, 2017.

14. Zhang X, Ai F, Li X, Tian L, Wang X, Shen S and Liu F: MicroRNA-34a suppresses colorectal cancer metastasis by regulating Notch signaling. Oncol Lett 14: 2325-2333, 2017.

15. Wu J, Wu G, Lv L, Ren YF, Zhang XJ, Xue YF, Li G, Lu X, Sun Z and Tang KF: MicroRNA-34a inhibits migration and invasion of colon cancer cells via targeting to Fra-1. Carcinogenesis 33: 519-528, 2012.

16. Li L, Yuan L, Luo J, Gao J, Guo J and Xie X: MiR-34a inhibits proliferation and migration of breast cancer through down-regulation of Bcl-2 and SIRT1. Clin Exp Med 13: 109-117, 2013.

17. Franchina T, Amodeo V, Bronte G, Savio G, Ricciardi GR, Picciotto M, Russo A, Giordano A and Adamo V: Circulating miR-22, miR-24 and miR-34a as novel predictive biomarkers to pemetrexed-based chemotherapy in advanced non-small cell lung cancer. J Cell Physiol 229: 97-99, 2014.

18. Cao W, Yang W, Fan R, Li H, Jiang J, Geng M, Jin Y and Wu Y: miR-34a regulates cisplatin-induce gastric cancer cell death by modulating PI3K/AKT/survivin pathway. Tumour Biol 35: 1287-1295, 2014.

19. Nugent M, Miller $\mathrm{N}$ and Kerin MJ: Circulating miR-34a levels are reduced in colorectal cancer. J Surg Oncol 106: 947-952, 2012.

20. Gao J, Li N, Dong Y, Li S, Xu L, Li X, Li Y, Li Z, Ng SS Sung JJ, et al: miR-34a-5p suppresses colorectal cancer metastasis and predicts recurrence in patients with stage II/III colorectal cancer. Oncogene 34: 4142-4152, 2015.

21. Livak KJ and Schmittgen TD: Analysis of relative gene expression data using real-time quantitative PCR and the 2(-Delta Delta C(T)) method. Methods 25: 402-408, 2001.

22. Liu C, Rangnekar VM, Adamson E and Mercola D: Suppression of growth and transformation and induction of apoptosis by EGR-1. Cancer Gene Ther 5: 3-28, 1998.

23. Calogero A, Arcella A, De Gregorio G, Porcellini A, Mercola D, Liu C, Lombari V, Zani M, Giannini G, Gagliardi FM, et al: The early growth response gene EGR-1 behaves as a suppressor gene that is down-regulated independent of $\mathrm{ARF} / \mathrm{Mdm} 2$ but not p53 alterations in fresh human gliomas. Clin Cancer Res 7: 2788-2796, 2001.

24. Levin WJ, Press MF, Gaynor RB, Sukhatme VP, Boone TC, Reissmann PT, Figlin RA, Holmes EC, Souza LM and Slamon DJ: Expression patterns of immediate early transcription factors in human non-small cell lung cancer. The Lung Cancer Study Group. Oncogene 11: 1261-1269, 1995.

25. Ahmed MM: Regulation of radiation-induced apoptosis by early growth response- 1 gene in solid tumors. Curr Cancer Drug Targets 4: 43-52, 2004.

26. Baron V, Adamson ED, Calogero A, Ragona G and Mercola D: The transcription factor Egrl is a direct regulator of multiple tumor suppressors including TGFbeta1, PTEN, p53, and fibronectin. Cancer Gene Ther 13: 115-124, 2006.

27. Virolle T, Adamson ED, Baron V, Birle D, Mercola D, Mustelin T and de Belle I: The Egr-1 transcription factor directly activates PTEN during irradiation-induced signalling. Nat Cell Biol 3: 1124-1128, 2001

28. Krones-Herzig A, Adamson E and Mercola D: Early growth response 1 protein, an upstream gatekeeper of the p53 tumor suppressor, controls replicative senescence. Proc Natl Acad Sci USA 100: 3233-3238, 2003.

29. Kim SO, Kwon JI, Jeong YK, Kim GY, Kim ND and Choi YH: Induction of Egr-1 is associated with anti-metastatic and anti-invasive ability of beta-lapachone in human hepatocarcinoma cells. Biosci Biotechnol Biochem 71: 2169-2176, 2007. 
30. Katsumoto T, Mitsushima A and Kurimura T: The role of the vimentin intermediate filaments in rat $3 \mathrm{Y} 1$ cells elucidated by immunoelectron microscopy and computer-graphic reconstruction. Biol Cell 68: 139-146, 1990.

31. McInroy L and Maatta A: Down-regulation of vimentin expression inhibits carcinoma cell migration and adhesion. Biochem Biophys Res Commun 360: 109-114, 2007.

32. Bargagna-Mohan P, Hamza A, Kim YE, Khuan Abby Ho Y, Mor-Vaknin N, Wendschlag N, Liu J, Evans RM, Markovitz DM, Zhan CG, et al: The tumor inhibitor and antiangiogenic agent withaferin A targets the intermediate filament protein vimentin. Chem Biol 14: 623-634, 2007.

33. Satelli A and Li S: Vimentin in cancer and its potential as a molecular target for cancer therapy. Cell Mol Life Sci 68: 3033-3046, 2011.

34. Lamouille S, Xu J and Derynck R: Molecular mechanisms of epithelial-mesenchymal transition. Nat Rev Mol Cell Biol 15: 178-196, 2014

35. Nieto MA: Epithelial plasticity: A common theme in embryonic and cancer cells. Science 342: 1234850, 2013.

36. Wrighton KH: Cell migration: EMT promotes contact inhibition of locomotion. Nat Rev Mol Cell Biol 16: 518, 2015.
37. Xiao S, Liu L, Lu X, Long J, Zhou X and Fang M: The prognostic significance of bromodomain PHD-finger transcription factor in colorectal carcinoma and association with vimentin and E-cadherin. J Cancer Res Clin 141: 1465-1474, 2015.

38. Toiyama Y, Yasuda H, Saigusa S, Tanaka K, Inoue Y, Goel A and Kusunoki M: Increased expression of Slug and Vimentin as novel predictive biomarkers for lymph node metastasis and poor prognosis in colorectal cancer. Carcinogenesis 34: 2548-2557, 2013.

39. Rokavec M, Öner MG, Li H, Jackstadt R, Jiang L, Lodygin D, Kaller M, Horst D, Ziegler PK, Schwitalla S, et al: IL-6R/STAT3/miR-34a feedback loop promotes EMT-mediated colorectal cancer invasion and metastasis. J Clin Invest 124: 1853-1867, 2014

(i) () () This work is licensed under a Creative Commons

cc. International (CC BY-NC-ND 4.0) License. 